\title{
ON THE MOVEMENTS OF THE INTESTINAL VILLI OF THE DOG
}

\author{
Ryozi Nanba, Seiko Hiramatsu \\ AND Katsushi MoRIMOTO* \\ Department of Physiology, Training Institute for Health-teachers, \\ Okayama University
}

When the internal surface of the small intestine is examined under warm saline solution by means of a low-powered microscope, it is seen that each of the villi is extending and contracting. It is generally believed that these movements accelerate the flow of blood and lymph and that they increase absorption, although KING, ARNOLD and CHURCH (1922) ${ }^{3)}$ were unable to find any evidence of these functions. More recent studies, especially those of von KOKAS and von LUDÁNY $(1939)^{9}$, leave little doubt that efficient absorption of food-stuffs from the intestine is dependent to some extent on the activity of the villi. The movements of the villi are partly under nervous control, being augmented by stimulation of the splanchnic though not of the vagus nerves. The movements of the villi, however, were not recorded on a mechanograph.

We have been able to record the movement of the villi on a mechanograph indirectly by a new method. The results are reported as follows.

\section{METHODS}

Dogs weighing $6-15 \mathrm{~kg}$ were anesthetized by an intravenous injection of Pentobarbital sodium $(20-25 \mathrm{mg} / \mathrm{kg})$, and the abdominal cavity was then opened with a mid-line incision. About $10-15 \mathrm{~cm}$. of the small intestine was drawn out and was opened by a longitudinal incision through the wall along its antimesenteric border.

The exposed small intestine was fixed on a cork board in a small bath with insect needles to stop the movement of intestinal wall, and the bath was placed under a stereoscopic microscope (Olympus, Tokyo) to which was attached a screw-micrometer in order to record the movement of a villus.

Continuously, TYRODE solution warmed to body temperature was poured over the exposed small intestine.

The screw-micrometer was connected by a thread to a force-displacement transducer (Nihon Kohden, SB-1T-H) which was connected to a carrier amplifier (Nihon Kohden, RP-3) (FIG. 1).

The screw-micrometer was composed of two-parts; one was a fixed graduation and

Received for publication May 9, 1970

* Department of Biology, Faculty of Science, Okayama University, Okayama, Japan.

難波良司, 平松誠子, 森元克士 


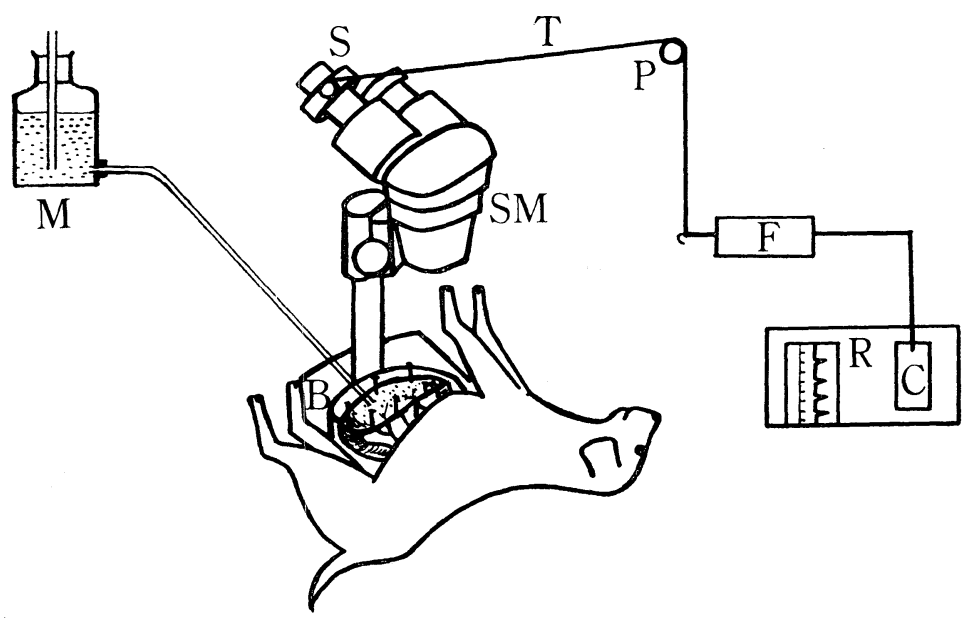

FIG. 1. Arrangement of the experimental apparatus. B: Bath. C: Carrier amplifier. F : Force-displacement transducer. M: Mariotte's bottle. P: Pully. R: Multipurpose recorder. S: Screw-micrometer. SM: Stereoscopic microscope. T: Cotton thread. Explanations in text.

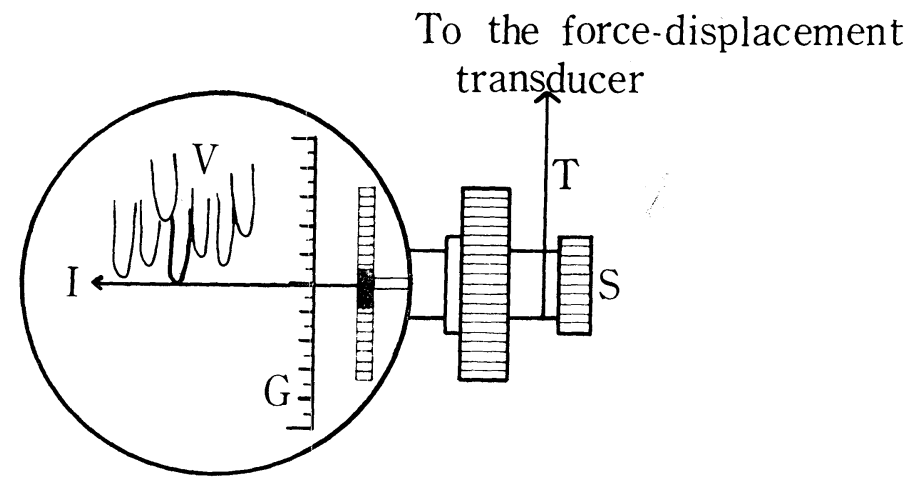

FIG. 2. Schema indicating the screw-micrometer. G: Fixed graduation. I : Movable indicator. S: Screw. T: Cotton thread. Explanations in text.

the other a movable indicator. The schema is shown in FIG. 2. The indicator of the screw-micrometer could be set against the tip of a villus through the stereoscopic microscope and could be moved easily by an observer turning the screw according to the movements of the villus.

When the screw of the screw-micrometer was moved following the movements of the villus, the movements were recorded automatically on recording paper.

In order to study the nervous innervation of the villus, electrical stimulation was applied to the cervical vagus nerve, the major splanchnic nerve, and the mesenteric E. nerve. The electrical stimulus was usually repetitive square waves $4.5 \mathrm{msec}$ in duration at a frequency of $20 / \mathrm{sec}$, and of various intensities.

The room temperature was kept at about $30^{\circ} \mathrm{C}$. 
1) The movements of the villus.

The villi of the duodenum are broader than those elsewhere, and many examples of leaf-like ones can be found in this region $\left(16-20 \mathrm{villi} / \mathrm{mm}^{2}\right)$. In the upper part of the jejunum, the villi, in general, are described as tongueshaped (30-35 villi $\left./ \mathrm{mm}^{2}\right)$. Further down the jejunum they become longer and finger-shaped $\left(54-60 \mathrm{villi} / \mathrm{mm}^{2}\right)$. There are many villi in the ileum, and their shape tends to be more slender (FIG. 3).

A

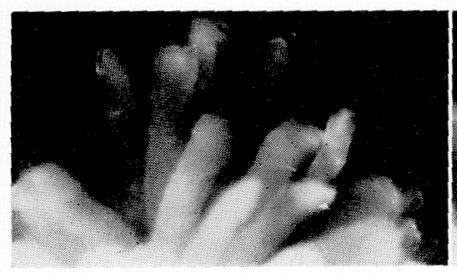

FIG. 3. Low-power photomicrograph $(\times 40)$ of the villi of a dog. A: The villi of the duodenum. B: The villi of the jejunum. C: The villi of the ileum. Explanations in text.

When TYRODE solution warmed to body temperature was poured over the internal surface of the small intestine, it could be seen that each of the villi moved independently without regard to the other villi.

Occasionally, a villus showed a slight swinging motion. The main movement, however, was lengthwise contraction. The contractions were rapid while the extensions took place more slowly. Such contractions and extensions were repeated about 10-28 times per minute. The period had no regularity unlike the cardiac cycle. When the villus contracted, it was shortened from $1 / 2$ to $1 / 4$ of its full length (FIG. 4).

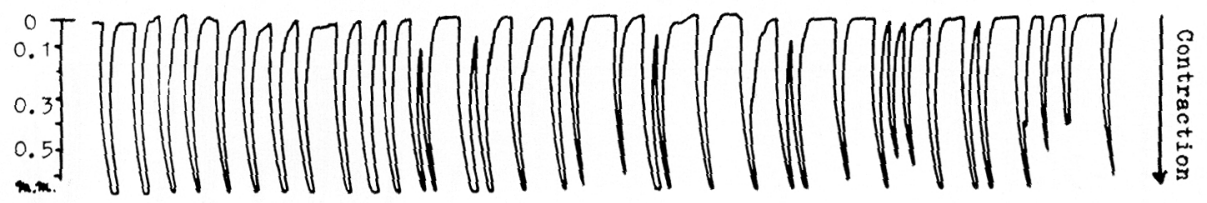

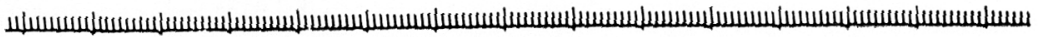

Fig. 4. The movements of the villus in the duodenum. The movements of the duodenal villus occurred about 10 to 28 times per minute. The calibration curve shown at the left indicates the contractile activity in $\mathrm{mm}$. Time is shown in one sec. intervals.

The activity of the villus movement was greater in the upper than in the lower part of the small intestine (FIG. 5). 

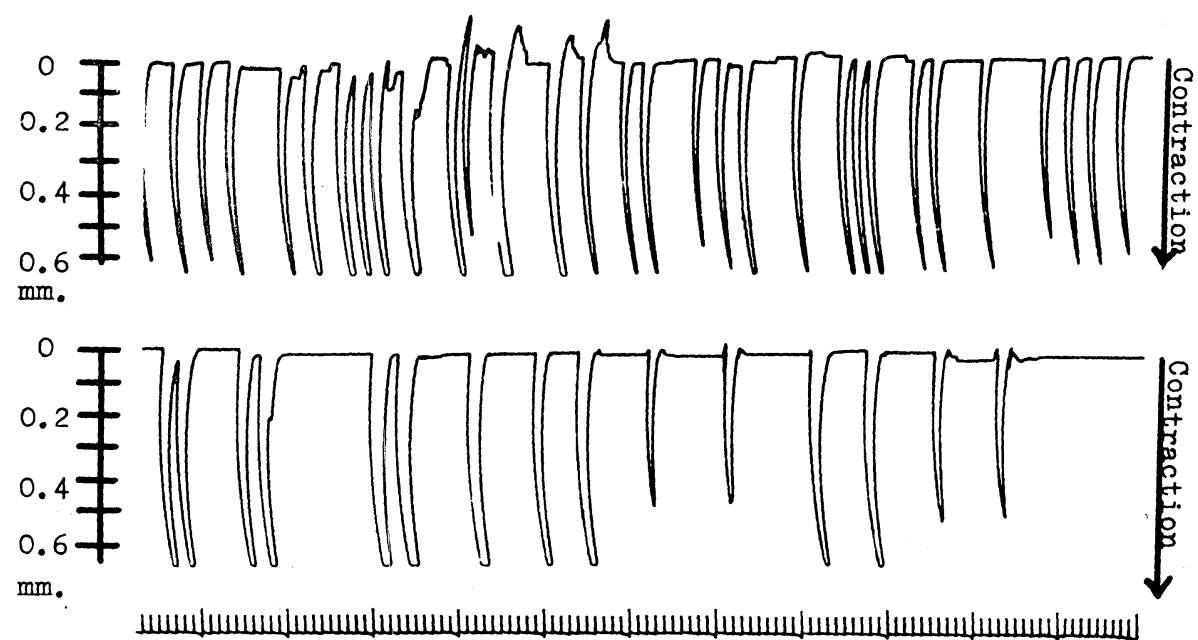

FIG. 5. The villus movements in the upper and lower part of the small intestine. The activity and the contractile frequency of the villus movement is greater in the upper than in the lower part of the intestine. Upper: Duodenal villus movement. Middle: Ileal villus movement. Lower: Time in one sec. intervals. The calibration curve shown at the left indicates the contractile activity in $\mathrm{mm}$.

When the tip of the villus was ligated with a silk thread, the movement was inhibited. From this fact, it may be said that the villus movement originates in the tip of the villus.

2) The effects of stimulating the autonomic nerves on the movements of the villus.

a) Effects of stimulation of the mesenteric nerve on the movements of the villi.

When the TYRODE solution was poured over the villi of the jejunum, they showed considerable movement. However when the mesenteric nerve which runs to the experimental jejunum was stimulated weakly, the color of the

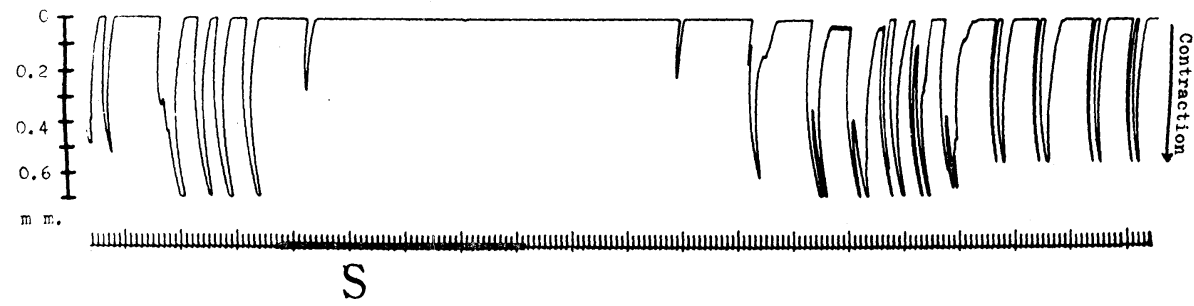

FIG. 6. Effects of stimulation of the mesenteric nerve on the movements of the villus. The electric stimulation (Freq. 20/sec., Duration $4.5 \mathrm{msec}$, and intensity 1 volt) was applied to the mesenteric nerve. The movements of the villus were completely inhibited. The calibration curve shown at the left indicates the contractile activity in $\mathrm{mm}$. S: Duration of stimulation. Time in one sec. intervals. 
villus was changed rapidly from deep pink to pale pink and the villus remained extended. The movements of the villus were inhibited completely as shown in FIG. 6.

When stronger stimulation was applied the movements of the villus were inhibited just as with weak stimulation.

b) Effects of stimulation of the vagus nerve on the movements of the villus.

When both strong and weak stimulation was applied to the cervical vagus nerve, the movement of the villus was slightly increased in frequency (FIG. 7).

No difference in stimulant effect on the movement of the villus was observed between the right and left vagus nerve.

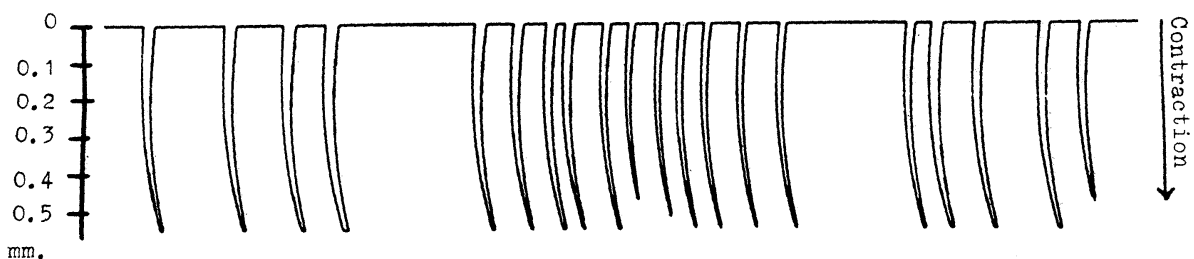

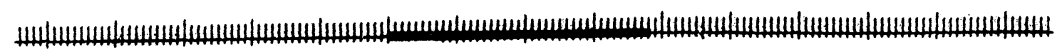

$\mathrm{S}$

FIG. 7. Effects of stimulation of the vagus nerve on the movements of villus. The electric stimulation (Freq. $20 / \mathrm{sec}$., Duration $4.5 \mathrm{msec}$. and 8 volt) was applied to the right cervical vagus nerve and the movement of the villus increased slightly in frequency. The calibration curve shown at the left indicates the contractile activity in $\mathrm{mm}$. S: Duration of stimulation. Time in one sec. intervals.

c) Effects of stimulation of the splanchnic nerve on the movements of the villus.

When the stimulation was applied to the splanchnic nerve extraperitoneally, the movement of the villus was also inhibited just as in the case of mesenteric nerve stimulation (FIG. 8).

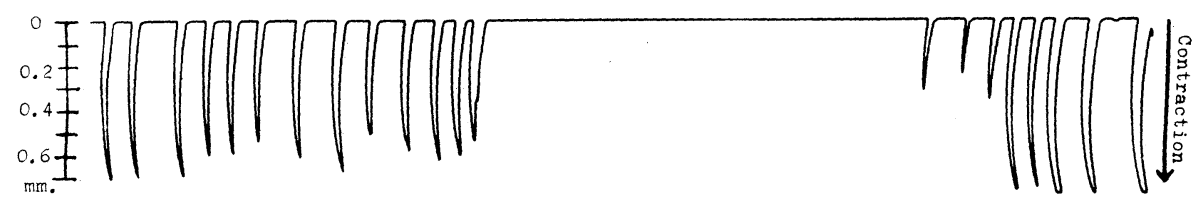

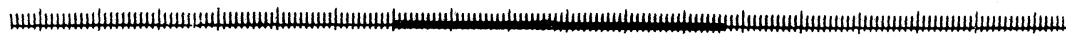

\section{S}

Fig. 8. Effects of stimulation of the splanchnic nerve on the movements of the villus. The electric stimulation (Freq. $20 / \mathrm{sec}$., Duration $4.5 \mathrm{msec}$. and 10 volt) was applied to the splanchnic nerve and the movements of the villus were inhibited. The calibration curve shown at the left indicates the contractile activity in $\mathrm{mm}$. S: Duration of stimulation. Time in 1 sec. intervals. 
The color of the villus was changed from pink to pale pink and the villus remained extended. The movement of the villus started again a short time after the stimulation was stopped.

\section{DISCUSSION}

The surface of the mucous membrane of the small intestine has an enormous number of villi. However, relatively little work has been done on the muscularis mucosae which is responsible for the motility of the villus. The movements of the villi were described by HAMBLETON $(1914)^{2)}$, and later by King, ARnold and Church $(1922)^{3)}$ and VERzÁR and KoKAS (1927) ${ }^{11)}$, KoKAS $(1930)^{5)}$ and KoKAS and LudÁNy $(1934)^{7,8)}$.

The movements of the villi of the jejunum were observed under a binocular microscope by KOKAS and LUdÁNY $(1930)^{6}$. In the dog, each villus shortens fairly quickly at irregular intervals and then relaxes slowly, contracting about six times per minute quite independently of its neighbours.

In the present experiments, we could confirm KoKAS and LudÁNY's observation. The frequency of the contractions of the villus, however, was generally from 10 to 28 times per minute. This difference in results may be due to two factors: the good unanemic condition of the small intestine and the fact that the villi in the duodenum are more active than those in the jejunum and ileum.

When the tip of a villus was ligated with a silk thread, the movements of the villus were inhibited completely. From this fact, it may be said that the movement of the villus originates in the tip of the villus, while further studies are to be made to attain the conclusion.

LUDÁNY and JOURDAN $(1935)^{10)}$ found that the stimulation of the splanchnic nerve increased the activity of the villus, whereas stimulation of the vagus nerve decreased the activity. However KING and Robinson (1945) ${ }^{4)}$ did not agree with LUDÁNY and JOURDAN ${ }^{10)}$ on vagus effects; they saw no complete cessation of movements due to stimulation of the vagus nerve.

In the present experiments, stimulation of the mesenteric and splanchnic nerves was found to inhibit the movements of the villus, and stimulation of the vagus to accelerate a little the frequency of the contraction of the villus. When electric stimulation was applied to the mesenteric nerve or splanchnic nerve, the movements of the villus were inhibited in a state of extension, and the color of the villus changed remarkably from deep pink to pale pink. The villus remained extended until after the stimulation was stopped. Further studies on difference of stimulating effect between splanchnic and mesenteric nerve are to be made in future studies.

Finally, the villi of the small intestine vary greatly in shape in different animals and in different parts of the bowel in agreement with BUJARD's 
report $t^{13}$

\section{SUMMARY}

The movements of the villi were studied in anesthetized dogs. The results are summarized as follows:

1. The villi shorten quickly at irregular intervals and then extend slowly, each villus contracting about 10-28 times per minute quite independently of its neighbours.

2. The activity of the villi is greater in the upper part than in the lower part of the small intestine.

3. Stimulation of the cervical vagus nerve caused a slight increase in the activity of the villus, while stimulation of the splanchnic nerve and mesenteric nerve inhibited its activity.

The authors are very grateful to Miss M.F. MCCRimmon and Prof. Takesi HukuHARA for their advice and reading of this manuscript.

\section{REFERENCES}

1) BujARD, E.: Etude des Types appendiciels de la muqueuse intestinale, en rapport avec les régimes alimentaires. Morphologie comparée. Sitiomorphoses naturelles et expérimentales. Internat. Monatsschrift Anat. Physiol., 26: 101-196, 1909.

2) Hambleton, B.F.: Note upon the movements of the intestinal villi. Am. J. Physiol., 34: 446-447, 1914.

3) King, C.E., Arnold, L. And Church, J.G.: The physiological role of the intestinal mucosal movements. Am. J. Physiol., 61: 80-92, 1922.

4) King, C.E. And Robinson, M.H.: The nervous mechanisms of the muscularis mucosae. Am. J. Physiol., 143: 325-335, 1945.

5) KoKas, E.: Vergleichend-physiologische Untersuchungen über die Bewegung der Darmzotten. Pfï̈gers Arch., 225 : 416-420, 1930.

6) KoKas, E. Und LudánY, G.V.: Weitere Untersuchungen über die Bewegung der Darmzotten. Pflügers Arch., 225 : 421-428, 1930.

7) KoKAs, E. UNd LudÁNY, G.V.: Die hormonale Regelung der Darmzottenbewegung. Pftügers Arch., 232: 293-298, 1933.

8) KoKas, E. Und Ludány, G.V.: Die hormonale Regelung der Darmzottenbewegung. II. Das Villikinin. Pfiugers Arch., $234:$ 182-186, 1934.

9) Kokas, E. und Ludány, G.V.: Weitere Untersuchungen über die nervöse Beeinflussung der Darmzottentätigkeit. Pfiigers Arch., 241: 268-271, 1939.

10) LudÁnY, G.V. ET JOURDAN, F.: Influences du pneumogastrique et du sympathique sur la motricité des villosités intestinales. C. r. Soc. Biol., 119: 1189-1190, 1935.

11) Verzár und KoKas, E.: Die Rolle der Darmzotten bei der Resorption. Pfiügers Arch., 217: 397-412, 1927. 